\title{
A Study on Family Strengths and Psychological Happiness as Perceived by Adults Based on Gender
}

\author{
In Kang1)
}

\begin{abstract}
The purpose of this research was to find out how adults perceive family strengths and psychological happiness. This research was conducted from February 27, 2017 to March 26, 2017 among 572 adult residents of Seoul. To examine differences in family strengths and psychological happiness, t-test and F-test were performed. The results of the research are as follows: first, among the adult respondents, males (mean score of 4.15) perceived family strengths more positively than females (mean score 3.80); second, the t-test result on the psychological happiness between gender showed a statistically significant difference $(\mathrm{t}=6.53$, $\mathrm{p}<.001)$ where males mean score was $4.09(\mathrm{SD}=.71)$ and females mean score was $3.80(\mathrm{SD}=.69)$, and; third, the correlation between overall family strengths and psychological happiness was positive, with a coefficient of .687. Among the family strengths subdomains, shared values and goals had the highest correlation with psychological happiness $(\mathrm{r}=664)$. The higher the family strengths are, the higher the psychological happiness is.

Keywords : Family Structure, Family Strengths, Psychological Happiness, Gender, Age
\end{abstract}

\section{Introduction}

During the industrialization period, the interests of individuals were focused on material wealth. Today in the information society, their interests shifted and increased on psychological happiness. Psychological happiness is a subjective perception of the emotional experience and attitude that nothing is lacking in life, and that self is psychologically comfortable. It refers to a state of mind that is sufficient satisfaction and joy in life. Seligman, the founder of positive psychology, defined a happy life as a life consisting of three elements which are 'joy based on positive emotion,' 'immersion in positive activities' and 'meaning in life'[1]. psychological happiness from an emotional perspective refers to the positive and joyful feeling one has towards life in terms of everyday activity[2].

Received(April 29, 2019), Review Result(1st: May 22, 2019, 2nd: July 23, 2019), Accepted(September 10, 2019)

1) (Professor) 01133 Dept. Elderly Welfare, School of Social Welfare, Seoul Cyber University, 60, Solmae-ro 49-gil, Gangbuk-gu, Seoul, Korea

email: drhome@iscu.ac.kr 
However, psychological happiness is not to be evaluated based on objective criteria because it often entails subjective aspects. Instead, it can be defined depending on the time, culture, and the individual's value system. Recently, it has been reported that psychological happiness is lower in Korean adults in comparison to adults in other countries[3]. Accordingly, the psychological happiness perceived by Korean adults should be investigated in detail.

On the other hand, Korea achieved economic development during industrialization, and in the process, family structure, function, and role changed, and diverse family types emerged. The Korea's traditional patriarchal family structure and function in Korea are causing problems as family conflict and high divorce rate increases today. Therefore, what is meant by the strong family in Korea should be re-examined.

In this context, family strengths are currently defined as families in which the members clearly communicate with other members In other words, in a strong family, the members have emotional bonds with one another, share the responsibility for family issues and have the will to resolve them, have a shared value system, and promote positive communication[4].

Research on family strengths began in the US in the late 1970s. Previously, most research on family focused on negative and pathological aspects. However, since the late 1970s, positive aspects in the family has become the focus of research in the area and theoretical and practical studies began to be conducted to understand what it is meant by a strong family[5].

Additionally, in Korea, interest in family strengths greatly increased with the Framework Act on Healthy Families enacted in 2004 to prevent various family problems occurring with the change in the traditional patriarchal family value system since industrialization.

That is, family strengths involve economic stability; stable access to food, clothing, and shelter; relationships based on democratic and gender equality among family members; open conversations; shared recreational and leisure activities; support for child rearing and development; rational resource management; shared roles in the family; work-family balance; healthy civic consciousness; and voluntary participation in activities[6].

In this context, the characteristics of family strength are devotion to family members, spending time together, being able to handle family members' stress, psychological well-being, positive communication, gratitude, and affection. Moreover, the elements of family strength include respect for family members, family bonding, gratitude and affection, positive communication, shared values and goals, role fulfillment, problem-solving ability, economic stability and cooperation, and bonds within the society.

Because family is the individual's primary environment and the foundation of growth and change, the strong family can be influential in the individuals' psychological happiness. For 
instance, it was found that family strengths and psychological happiness perceived by adults are positively correlated with each other and that the happiness index is higher in college students spending a lot of time with family[7]. Accordingly, there is a need to investigate the relationship between psychological happiness and family strengths.

The present study was conducted among adults aged between 20 and 60 years living in Seoul in order to investigate, first, whether there is a difference in family strengths perceived by male and female adults; second, whether there is a difference in psychological happiness perceived by male and female adults and; third, the relationship between family strengths and psychological happiness.

\section{Research Method}

This study was conducted from February 27, 2017 to March 26, 2017 based on the survey among 572 adult male and female residents in Seoul. The measurement instruments used in the present study consisted of a total of 50 items, including those regarding family strengths, psychological happiness, and socio-demographic variables.

The scale for family strengths was revised from the scale developed by Yoo[8], while the scale for psychological happiness used the items developed by Song[3]. Both scales were based on Five Point Likert Scale, with "highly likely" receiving 5 points and "highly unlikely" receiving 1 point. The higher the score, the higher were the family strengths and psychological happiness levels. Table 1 shows that family strengths scale consists of 27 items which consist of sub-variables of respect for family members, bonding consciousness, appreciation and affection, positive communication, sharing values and goals, enhancing role, problem-solving ability, economic stability, bonds with society. The psychological happiness scale consists of 20 items.

[Table 1] Contents of The Questionnaire

\begin{tabular}{|c|l|}
\hline Variables & \multicolumn{1}{c|}{ Sub-variables and Items } \\
\hline $\begin{array}{c}\text { Family } \\
\text { Strengths }\end{array}$ & $\begin{array}{l}\text { respect for family members, bonding consciousness, appreciation and } \\
\text { affection, positive communication, sharing values and goals, enhancing } \\
\text { role, problem-solving ability, economic stability, bonds with society }\end{array}$ \\
\hline Psychological & $\begin{array}{l}\text { I am confident with the decisions I make. } \\
\text { I can argue for what I think. } \\
\text { I think I am a capable person. } \\
\text { Additional 17 items }\end{array}$ \\
\hline $\begin{array}{c}\text { Socio- } \\
\text { demographic } \\
\text { Characteristics }\end{array}$ & gender, age, family structure \\
\hline
\end{tabular}


The data were analyzed in the following manner using SPSS/PC 24.0. First, item reliability was tested by computing Cronbach's alpha. Table 2 presents that the reliability coefficients of family strengths and psychological happiness were over .95 in both cases, demonstrating inter-item internal consistency. Second, frequencies, percentages, and the means were computed for social-demographic characteristics of study subjects. Third, t-test and F-test were performed to examine differences in family strengths and psychological happiness according to subjects' social-demographic characteristics. Fourth, a correlational analysis was conducted to examine the relationship between family strengths and psychological happiness.

[Table 2] Contents of the Questionnaire

\begin{tabular}{|c|c|c|}
\hline Variables & Sub-Variables & Cronbach's a \\
\hline \multirow{5}{*}{ Family } & respect for family members & .957 \\
\cline { 2 - 3 } & bonding consciousness & .956 \\
\cline { 2 - 3 } Strengths & appreciation and affection & .956 \\
\cline { 2 - 3 } & positive communication & .956 \\
\cline { 2 - 3 } & sharing values and goals & .956 \\
\cline { 2 - 3 } & Enhancing role & .957 \\
\cline { 2 - 3 } & problem-solving ability & .959 \\
\cline { 2 - 3 } & economic stability & .960 \\
\cline { 2 - 3 } & bonds with society & .968 \\
\hline \multicolumn{2}{|c|}{ Psychological Happiness } & .962 \\
\hline
\end{tabular}

\section{Results}

\subsection{Socio-demographic Characteristics of Study Subjects}

Table 3 shows that frequencies and percentages were calculated for the social-demographic characteristics of study subjects. The subjects were 572 respondents of which 325 (56.8\%) were female, and $247(43.2 \%)$ were male. According to age, $271(47.4 \%)$ were aged between 20 and 40 years, and $301(52.6 \%)$ were between 41 and 60 years. Based on the family type where the respondents belong to, $385(67.5 \%)$ lived in a nuclear family, $82(14.3 \%)$ in an extended family, $60(10.5 \%)$ in a single-parent family, $25(4.4 \%)$ in a single-person family, and $20(3.4 \%)$ in other types of family. 
[Table 3] Socio-demographic Characteristics of The Subjects http://dx.doi.org/10.21742/apjcri.2019.09.14

\begin{tabular}{|c|c|c|c|}
\hline Variables & Category & Frequency & $\%$ \\
\hline \multirow{3}{*}{ Gender } & Male & 247 & 43.2 \\
\cline { 2 - 4 } & Female & 325 & 56.8 \\
\hline \multirow{4}{*}{ Age } & $20-40$ & 271 & 47.4 \\
\cline { 2 - 4 } Family & $41-60$ & 301 & 52.6 \\
\cline { 2 - 4 } & Nuclear family & 385 & 67.4 \\
\cline { 2 - 4 } & Extended family & 82 & 14.3 \\
\cline { 2 - 4 } & $\begin{array}{c}\text { Single-parent } \\
\text { family }\end{array}$ & 60 & 10.5 \\
\cline { 2 - 4 } & $\begin{array}{c}\text { Single-person } \\
\text { family }\end{array}$ & 25 & 4.4 \\
\cline { 2 - 4 } & Other & 20 & 3.4 \\
\hline
\end{tabular}

\subsection{Difference in Family Strengths according to Socio-demographic Characteristics of Study Subjects}

For social-demographic characteristics of study subjects, gender, age, and family type were examined. First, to examine family strengths according to gender, $\mathrm{t}$-test was conducted for the following nine subdomains of family strengths: respect for family members, family bonding, gratitude and affection, positive communication, shared values and goals, role fulfillment, problem-solving ability, economic stability, and bonds within the society. Table 4 presents that the mean score of overall family strengths was $4.15(\mathrm{SD}=.66)$ and $3.80(\mathrm{SD}=.67)$ in males and females, respectively $(t=6.08, p<.001)$. That is, male adults had higher levels of perceived family strengths compared to female adults. This finding is consistent with that of a previous study that the perceived level of family strengths was higher in male than female students[7]. Additionally, a statistically significant gender difference was found in all nine subdomains of family strengths (respect for family members, family bonding, gratitude and affection, positive communication, shared values and goals, role fulfillment, problem-solving ability, economic stability, and bonds within the society). The mean score for family strengths was higher than the midpoint in the Five Likert Scale in both males and females, and thus, the perceived level of family strengths was high overall in both genders. Of the family strengths subdomains, family bonding scored the highest in males, while problem-solving ability scored the highest in females. 
[Table 4] Gender Difference in Family Strengths

\begin{tabular}{|c|c|c|c|}
\hline \multirow{2}{*}{ Family Strengths } & Male(N=247) & Female(N=325) & \multirow{2}{*}{$\mathrm{t}$} \\
\cline { 2 - 3 } & $\mathrm{M}(\mathrm{SD})$ & $\mathrm{M}(\mathrm{SD})$ & $6.08^{\text {***}}$ \\
\hline total & $4.15(.66)$ & $3.80(.67)$ & $5.44^{\text {*** }}$ \\
\hline $\begin{array}{c}\text { respect for family } \\
\text { members }\end{array}$ & $4.47(.75)$ & $4.09(.86)$ & $5.26^{\text {*** }}$ \\
\hline family bonding & $4.49(.78)$ & $4.12(.85)$ & $4.96^{* * *}$ \\
\hline gratitude and affection & $4.44(.75)$ & $4.10(.85)$ & $5.71^{\text {*** }}$ \\
\hline positive communication & $4.21(.82)$ & $3.79(.89)$ & $5.54^{\text {*** }}$ \\
\hline shared values and goals & $4.15(.82)$ & $3.77(.82)$ & $4.48^{\text {*** }}$ \\
\hline role fulfillment & $4.42(.77)$ & $4.11(.83)$ & $4.07^{\text {*** }}$ \\
\hline problem-solving ability & $4.41(.68)$ & $4.17(.69)$ & $6.16^{\text {*** }}$ \\
\hline economic stability & $4.29(.74)$ & $3.87(.85)$ & $4.74^{\text {*** }}$ \\
\hline bonds within the society & $3.80(1.00)$ & $3.42(.91)$ & \\
\hline
\end{tabular}

$* * * p .001$

To examine family strengths according to age, t-test was performed for the same subdomains of family strengths above, i.e., respect for family members, family bonding, gratitude and affection, positive communication, shared values and goals, role fulfillment, problem-solving ability, economic stability, and bonds within the society. Table 5 shows that a significant age difference was not found in any of the subdomains, a finding consistent with the previous result that family strengths did not differ across different age groups[9].

[Table 5] Age Difference in Family Strengths

\begin{tabular}{|c|c|c|c|}
\hline \multirow{2}{*}{ Family Strengths } & \multicolumn{2}{|c|}{ Age } & \multirow{2}{*}{$\mathrm{t}$} \\
\cline { 2 - 3 } & $20-40(\mathrm{~N}=271)$ & $41-60(\mathrm{~N}=301)$ & .48 \\
\hline total & $3.96(.76)$ & $3.93(.61)$ & .41 \\
\hline $\begin{array}{c}\text { respect for family } \\
\text { members }\end{array}$ & $4.27(.88)$ & $4.24(.79)$ & -.32 \\
\hline family bonding & $4.27(.92)$ & $4.29(.76)$ & -.19 \\
\hline gratitude and affection & $4.24(.90)$ & $4.25(.75)$ & 1.22 \\
\hline positive communication & $4.02(.93)$ & $3.93(.83)$ & .18 \\
\hline shared values and goals & $3.94(.90)$ & $3.92(.78)$ & -.61 \\
\hline role fulfillment & $4.22(.90)$ & $4.27(.74)$ & .53 \\
\hline problem-solving ability & $4.29(.75)$ & $4.26(.64)$ & 1.41 \\
\hline economic stability & $4.10(.88)$ & $4.00(.88)$ & 1.21 \\
\hline bonds within the society & $3.64(1.06)$ & $3.54(.87)$ & \\
\hline
\end{tabular}

[Table 6] presents that statistically significant differences were found $(F=2.78, p<.05)$. Duncan post-hoc test revealed that the perceived level of family strengths was lower in subjects living in a single-person family compared to those living in a nuclear, extended, or single-parent 
family or in other type of family. At the subdomain level, problem solving ability $(\mathrm{F}=2.62$, $\mathrm{p}<0.5)$, economic stability $(\mathrm{F}=4.52, \mathrm{p}<.001)$, and bonds within the society $(\mathrm{F}=3.77, \mathrm{p}<.001)$ showed significant differences according to family type. The results of Duncan post-hoc test show that the perceived level of family strengths in subdomains of problem solving ability, economic stability and bonds within the society was lower in subjects living in a single-person family compared to those living in a nuclear, extended, single-parent, or other type family.

[Table 6] Family Structure Difference in Family Strengths

\begin{tabular}{|c|c|c|c|c|c|c|}
\hline \multirow{2}{*}{ Family Strengths } & 1 & 2 & 3 & 4 & 5 & \multirow{2}{*}{$\mathrm{F}$} \\
\cline { 2 - 6 } & $\mathrm{M}(\mathrm{SD})$ & $\mathrm{M}(\mathrm{SD})$ & $\mathrm{M}(\mathrm{SD})$ & $\mathrm{M}(\mathrm{SD})$ & $\mathrm{M}(\mathrm{SD})$ & \\
\hline total & $3.95(.65)$ & $4.01(.70)$ & $3.92(.70)$ & $3.54(.87)$ & $4.13(.79)$ & $2.78^{*}$ \\
\hline $\begin{array}{c}\text { respect for family } \\
\text { members }\end{array}$ & $4.27(.79)$ & $4.34(.81)$ & $4.17(.93)$ & $3.85(1.03)$ & $4.30(1.03)$ & 1.91 \\
\hline family bonding & $4.29(.79)$ & $4.32(.88)$ & $4.22(.92)$ & $3.90(1.10)$ & $4.43(.94)$ & 1.54 \\
\hline gratitude and affection & $4.27(.79)$ & $4.23(.86)$ & $4.30(.78)$ & $3.76(1.03)$ & $4.30(1.03)$ & 2.37 \\
\hline positive communication & $3.97(.88)$ & $4.06(.81)$ & $3.94(.88)$ & $3.60(1.07)$ & $4.28(.98)$ & 1.93 \\
\hline shared values and goals & $3.93(.83)$ & $4.07(.84)$ & $3.87(.75)$ & $3.50(.97)$ & $4.05(1.03)$ & 2.35 \\
\hline role fulfillment & $4.26(.81)$ & $4.33(.78)$ & $4.17(.76)$ & $3.82(1.06)$ & $4.45(.86)$ & 2.33 \\
\hline problem-solving ability & $4.30(.67)$ & $4.29(.70)$ & $4.25(.69)$ & $3.84(.81)$ & $4.25(.70)$ & $2.62^{*}$ \\
\hline economic stability & $4.07(.82)$ & $4.12(.76)$ & $3.92(.83)$ & $3.48(.92)$ & $4.40(.88)$ & $4.52^{* * *}$ \\
\hline bonds within the society & $3.54(.92)$ & $3.65(.99)$ & $3.75(.1 .01)$ & $3.18(1.17)$ & $4.20(1.03)$ & $3.77^{* *}$ \\
\hline
\end{tabular}

1= Nuclear family $(\mathrm{N}=385), 2=$ Extended family $(\mathrm{N}=82), 3=$ Single-parent family $(\mathrm{N}=60)$,

$4=$ Single-person family $(\mathrm{N}=25), 5=$ Other $(\mathrm{N}=20)$

${ }^{*} \mathrm{p}<0.05,{ }^{* * \mathrm{P}}<0.01,{ }^{* * * \mathrm{P}}<0.001$

\subsection{Difference in Psychological Happiness according to Socio-demographic Characteristics of Study Subject}

The difference in psychological happiness according to the general characteristics of subjects were examined using t-test and F-test, as shown in Table 7. The $\mathrm{t}$-test used to examine the psychological happiness according to gender showed a statistically significant difference $(t=6.52$, $\mathrm{p}<.001)$. The mean score of psychological happiness was $4.09(\mathrm{SD}=.71)$ and $3.70(\mathrm{SD}=.69)$ in males and females, respectively. That is, male adults had higher levels of psychological happiness compared to female adults. The finding agrees with that of a previous study conducted on psychological happiness in college students, where male students had a higher level of psychological happiness than female students[10]. The t-test used to examine the psychological happiness according to age did not show a statistically significant difference. The F-test conducted to examine psychological happiness according to family type showed no 
significant difference at all.

[Table 7] Gender, Age, Family Structure Difference in Psychological Happiness

\begin{tabular}{|c|c|c|c|c|}
\hline Variables & Category & $\mathrm{M}$ & SD & $\mathrm{t} / \mathrm{F}$ \\
\hline \multirow{2}{*}{ Gender } & Male & 4.09 & .71 & \multirow{2}{*}{$6.52^{* * *}$} \\
\hline & Female & 3.70 & .69 & \\
\hline \multirow{2}{*}{ Age } & $20-40$ & 3.90 & .79 & \multirow{2}{*}{.83} \\
\hline & $41-60$ & 3.85 & .66 & \\
\hline \multirow{5}{*}{$\begin{array}{l}\text { Family } \\
\text { structure }\end{array}$} & Nuclear family & 3.87 & .72 & \multirow{5}{*}{1.10} \\
\hline & Extended family & 3.94 & .69 & \\
\hline & $\begin{array}{l}\text { Single-parent } \\
\text { family }\end{array}$ & 3.87 & .75 & \\
\hline & $\begin{array}{l}\text { Single-person } \\
\text { family }\end{array}$ & 3.63 & .69 & \\
\hline & Other & 4.03 & .90 & \\
\hline
\end{tabular}

${ }^{* * *} \mathrm{p}<.001$

\subsection{Relationship between Family Strengths and Psychological Happiness}

Correlational analysis was performed to examine the relationship between family strengths and psychological happiness. [Table 8] presents that the correlation between overall family strengths and psychological happiness was positive, with a coefficient of .69 , and among the family strengths subdomains, shared values and goals had the highest correlation with psychological happiness $(\mathrm{r}=.66)$. That is, individuals experience psychological happiness when they perceive that their family members share the values that they hold.

In addition, all other subdomains of family strengths were correlated with psychological happiness at the level of $p<.001$. These findings are consistent with those of a previous finding that family strengths and psychological happiness perceived by adolescents were positively correlated[3].

To summarize, family strengths are positively correlated with psychological happiness in all the areas, and the higher family strengths, the higher is the psychological happiness.

\section{Conclusions}

Based on the analysis of the data used in the study, it revealed the following conclusions: First, female adults had lower levels of perceived family strengths than male adults did, in all subdomains. Moreover, the perception of "bonds within the society" among the subdomains 
[Table 8] Correlation of Family Strengths and Psychological Happiness

\begin{tabular}{|c|c|c|c|c|c|c|c|c|c|c|}
\hline & \multicolumn{10}{|c|}{ Family Strengths } \\
\hline & total & $\begin{array}{c}\text { respect for } \\
\text { family } \\
\text { members }\end{array}$ & $\begin{array}{c}\text { family } \\
\text { bondin } \\
\mathrm{g}\end{array}$ & $\begin{array}{l}\text { gratitud } \\
\text { e and } \\
\text { affection }\end{array}$ & $\begin{array}{l}\text { positive } \\
\text { communi } \\
\text { cation }\end{array}$ & $\begin{array}{c}\text { shared } \\
\text { values } \\
\text { and goals }\end{array}$ & $\begin{array}{c}\text { role } \\
\text { fulfillment }\end{array}$ & $\begin{array}{c}\text { problem } \\
\text { solving } \\
\text { ability }\end{array}$ & $\begin{array}{c}\text { economic } \\
\text { stability }\end{array}$ & $\begin{array}{c}\text { bonds } \\
\text { within } \\
\text { the } \\
\text { society }\end{array}$ \\
\hline $\begin{array}{c}\text { Psychologica } \\
1 \text { happiness }\end{array}$ & $.69^{* * *}$ & $.57^{* * *}$ & $.57^{* * *}$ & $.58^{* * *}$ & $.61^{* * *}$ & $.66^{* * *}$ & $.60^{* * *}$ & $.56^{* * *}$ & $.59^{* * *}$ & $.55^{* * *}$ \\
\hline
\end{tabular}

*** $\mathrm{p}<.001$

was the lowest in both males and females. Therefore, to promote family strengths, strategies should be explored to strengthen the ties between the family and systems external to the family. Additionally, strategies to enhance family strengths in female adults should be developed.

Second, the analysis of the difference in family strengths according to age showed that the perception of family strengths did not differ in young adults and middle-aged adults. The present study was conducted only with young and middle-aged adults living in Seoul, and thus, future research on family strengths should be expanded to include other geographical areas and age groups.

Third, subjects who belong in a single-person family had relatively lower levels of perceived family strengths compared to those who belong in other types of families. This finding can be interpreted as showing that individuals may voluntarily live as a single-person family because their perception of family strength is low. Therefore, family strengths should be measured separately for those in single-person families and other family types. That is, future research should be conducted to address the question of how to understand family strengths in the gradually increasing single-person families.

Fourth, psychological happiness was lower in female adults than in male adults. Therefore, strategies to improve the psychological happiness of female adults should be developed. There was no significant difference in psychological happiness by age or family type. However, psychological happiness may differ according to other general characteristic of the subjects. Follow-up research should be conducted to investigate the effects of diverse general characteristic like education level and income on psychological happiness.

Fifth, family strengths and psychological happiness were significantly positively correlated. Hence, various policies and practical models should be developed to increase family strengths and psychological happiness. At the same time, the causal relationship between family strengths 
and psychological happiness should be examined. Future research should investigate the relationship between family strengths and happiness by examining other general characteristics, such as income and education level in adults sampled from diverse geographic areas.

\section{References}

[1] Ed Diener, Martin E. P. Seligman, Beyond Money: Toward an economy of well-being, Psychological Science in The Public Interest, (2004), Vol.5, No.1, pp.1-31, DOI: https://doi.org/10.1111/j.0963-7214.2004.00501001.x

[2] R. Veenhoven, Questions on happiness: Classical topics, modern answers, blind spots, Subjective Well-Being: an interdisciplinary perspective, Pergamon Press, (1991)

[3] Song In Suk, The Effects of Family Strengths on Happiness Perceived by College Students, Wonkwang University, Master's Thesis, (2011), pp.11-12.

[4] John DeFrain and Sylvia M. Asay, Family Strengths and Challenges in the USA, Marriage and Family Review, (2007), Vol.41, No.3-4, pp.281-307, DOI: https://doi.org/10.1300/J002v41n03_04

[5] David H. Olson and John DeFrain, Marriage and families: diversity and strengths, McGraw-Hill Higher Education, (2003)

[6] Yoo Young Ju, A Study on the Development of Korean Family Strenths Scale for Strengthening the Family, Journal of Family Relations, (2004), Vol.9, No.2, pp.119-151, UCI: G704-001334.2004.9.2.010

[7] Lee Cho Eun, The Effect of self-esteem on the relationship between family strenght and career matutity in university students, Songwon University, Master's Thesis, (2019)

[8] Yoo Young Ju, A Discussion on the Concept of Sound Home and Healthy Family, Journal of Korean Home Management Association, (2012), Vol.17, No.3, pp.93-102.

[9] Jun Mi Ok, The Effect of Family Strength on Happiness perceived by the Adolescents, Kook Min University, Master's Thesis, (2012)

[10] Jung Gi Un, The Influence of Family Strength and Subjective Well-being on School Life Adaptation of Middle School Students, ChungBook University, Master's Thesis, (2016) 